\title{
EL MARX DE GUDYNAS: SOBRE LA IDEA DE MODOS DE APROPIACIÓN Y MODOS DE PRODUCCIÓN
}

\author{
Javier Enrique Zúñiga Tapia ${ }^{1}$
}

\section{Resumen/Abstract}

El artículo se propone abordar críticamente una argumentación presentada por Eduardo Gudynas: el concepto de "modo de apropiación" complementa y a la vez critica al concepto de origen marxiano de "modo de producción", siendo además más útil a la hora de dar cuenta de las realidades de los extractivismos en América Latina. Sin embargo, nuestra perspectiva considera que Gudynas opera sobre una idea restringida de lo que es "modo de producción" para Marx, por lo que proponer un "complemento", basándose en falsas ausencias, es incongruente con su crítica. Sugerimos en cambio una lectura atenta a algunos elementos teóricos del pensador alemán referidos al modo de producción que, estimamos, puede ayudar a orientar la crítica a los extractivismos y captar sus especificidades.

Palabras clave: Gudynas, Marx, modos de apropiación, modos de producción.

THE MARX OF GUDYNAS: ON THE IDEA OF APPROPRIATION MODES AND PRODUCTION MODES

The article intends to critically address an argument presented by Eduardo Gudynas: the concept of "mode of appropriation" that complements and criticizes the Marxian concept of "mode of production", which is more useful when accounting for extractivist in Latin America. However, our perspective considers that Gudynas operates on a restricted idea of what is a "mode of production" for Marx, so proposing a "supplement" based on false absences is inconsistent with his criticism. Instead, a close reading of some theoretical elements of the German thinker referring to the mode of production can help guide the critique of extractivist and capture their specificities.

Keywords: Gudynas, Marx, mode of appropriation, mode of production.

\footnotetext{
${ }^{1}$ Universidad Católica de Chile. E-mail: jqzuniga@uc.cl
} 


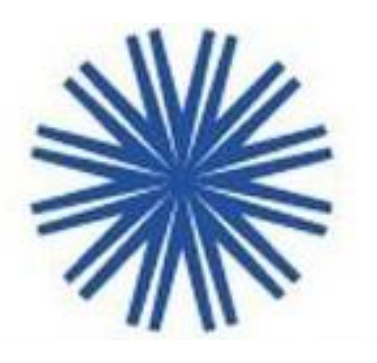

\section{Introducción}

La situación es apremiante: el planeta, y regiones enteras en él, viven los estragos de la degradación socio ambiental provocada por la actividad humana. Cada vez más urgencia y menos tiempo para reaccionar. Sobre sus causas se han dicho toda clase de cosas, desde los diversos negacionismos hasta las teorías más optimistas sobre lo que el colapso ambiental depararía. El mundo académico y de activistas del mundo académico han tomado también partido en el debate, constatando que se trata de un problema que no sólo es económico, político, socio ambiental, y tal vez todo ello junto, sino también epistemológico.

Se discute no solo las formas de explicar los impactos de esta actividad humana que socava la vida social y ambiental, sino también los puntos de partida conceptuales que permiten captar esta realidad, representarla en discursos críticos y convertirse en un instrumento teórico de acción, resistencia, reconstrucción. Allí emergen diversas corrientes, configurando distintas premisas de interpretación. Más allá de las diferencias, es necesario que esta pluralidad de posicionamientos exista, pues justamente habilitan la posibilidad de refinar los mecanismos críticos puestos en función del debate y la acción.

Sin embargo, entre ellas no solo debe haber debate, sino, principalmente, conocimiento recíproco. Discutir para esclarecer puntos de vista y, sobre todo, explicar mejor la realidad. Lamentablemente, tiende a primar otra lógica: la negación de otras posiciones sin siquiera indagar en los elementos de fondo que las construyen. Circulan entonces caricaturas, torsiones mediocres e incluso en ocasiones malintencionadas. Evidentemente, hay suficientes excepciones a esa tendencia. Con todo, quisiéramos llamar la atención de que tales actitudes clausuran la deliberación y contienen un germen, al menos potencial, pero preocupante desde el punto de vista académico y político, de "autoritarismo epistemológico", pues representan una versión suave, pero insistente, de exclusión de otras corrientes de pensamiento crítico en los propios movimientos sociales.

Quisiéramos ilustrar esto con un ejemplo. Tomemos un artículo de Eduardo Gudynas, conocido pensador crítico y activista cuyo trabajo, sin duda alguna, ha sido de utilidad para organizaciones que se encuentran confrontando los efectos del deterioro socio ambiental y a sus responsables (Gudynas, 2016). Es importante dejar en claro quién es Gudynas, destacar ese aporte. Únicamente, se pretende debatir los límites que presenta a la hora de sostener lo que él considera el legado teórico de Marx. Por supuesto, no 
se trata de una defensa doctrinaria, pues reconocemos que efectivamente muchas corrientes que se denominan a sí mismas marxistas, son de hecho productivistas y/o desconocen el sentido radical de la crítica de sectores antiextractivistas no marxistas o la propia profundidad de la situación de emergencia socio ambiental. Sin embargo, extender esas críticas a Marx no hacen justicia a lo planteado por él y, más aún, a los contenidos propuestos por él que, a nuestro juicio, permiten una lectura radical de la crisis ambiental y que sugieren elementos para transformarla. No los únicos, insistiremos en ello; se puede estar en desacuerdo con ellos.

No suponemos en este artículo que en Marx se encuentren respuestas unívocas, definitivas, para una teoría ecológica, eso está relativamente claro tanto para detractores y afines al pensador socialista El propósito es más modesto: identificar y argumentar sus proposiciones de forma más sistemática que lo hecho por Gudynas y poner en su lugar, en cambio, el momento específico de la trayectoria teórica en que Marx produjo.

\section{Modo de producción/modos de apropiación}

En el artículo referido, Gudynas se refiere a la existencia y proliferación de múltiples "extractivismos mineros, petroleros, agrícolas" (Gudynas, 2016: 96). Con ello pretende dar cuenta de la pluralidad de modos de organizar la producción e incluso de las multifacéticas experiencias al interior de cada rama productiva. Actividades cuya intensidad y extensión además muestran que el "extractivismo" es en verdad un conjunto de realidades variables según tipos de yacimiento, condiciones geográficas y geológicas, modos de organizar la fuerza de trabajo en cada enclave, variantes de prácticas institucionales, producción de metabolismos socio ambientales, etc.

En relación a todo lo mencionado anteriormente hay cierto acuerdo entre las corrientes críticas del extractivismo e incluso más allá de ellas. Ahora bien, para examinar estas realidades diversas, Gudynas propone el concepto "Modos de Apropiación” (MA), abstracción que no obstante él considera con el potencial de enriquecerse con determinaciones concretas. En ese sentido, se podría catalogar como un concepto mucho más "histórico" que el de "Modo de Producción" (MP), por lo tanto, con mayor rendimiento analítico a la hora de captar y explicar las realidades extractivistas. Con todo, según Gudynas, el MA se basa en el MP, se complementa en términos lógicos e históricos. Técnicamente, lo que él propone es que la interacción entre "sociedad y naturales" se articula a través de modos de apropiación entre 
distintos modos de producción, siendo el capitalista uno entre tantos, como el comunismo primitivo, modo de producción asiático, antiguo, feudal y el capitalista (Gudynas, 2016: 97).

El alto nivel de abstracción del concepto MP, habilitaría a Gudynas a complementarlo con el de MA, para explicar la particularidad, por ejemplo, de una realidad como la americana. Sin embargo, consideramos que esa es una forma muy simple de desplazar la relevancia del concepto de MP. No porque este explique todo, sino que su forma de abstracción no tiene que ver con un novel de generalidad, sino con un modo de analizar los núcleos constitutivos de la sociedad movilizada por el capital: mecanismos en que el valor se valoriza y las categorías que permiten construir un andamiaje teórico que explica ese proceso (se volverá sobre el punto). De esta manera, omitir esta perspectiva a la hora de buscar anclar conceptos supuestamente complementarios, resulta una opción teórica analíticamente inconsistente. Una opción entre muchas, pero que, como se argumentará, no es la opción más congruente con lo planteado por Marx.

Modo de producción tiene que ver en Marx con formaciones tendenciales que la vida social organiza y reproduce para su supervivencia y prolongación como especie. Es cierto que Gudynas releva y discute con una de las nociones más difundidas al respecto, con los "grandes modos de producción", pero es necesario destacar que ella es un producto sistematizado por la ideología-propaganda oficial del Estado Soviético, en la cual el evolucionismo y la linealidad histórica coronada por el estado burocrático, era el centro legitimador de la argumentación. Por el contrario, en Marx era otro el enfoque. Huelga decir que más que explicar conceptos, para Marx lo principal era la captación de los mecanismos concretos de interacción social, tarea a la que se subordinaban los conceptos. Este objetivo lo privó de producir grandes modelos explicativos o reeditar viejas/nuevas filosofías de la historia, las que, por cierto, fueron permanentemente desmontadas por él. Gudynas, en cambio, parece tomar otra versión, una orientación mucho menos enfatizada por Marx, para constatar un supuesto límite analítico desde donde construir nuevas proposiciones, como los MA.

Así, el problema no son las proposiciones de Gudynas, él tiene todo el derecho y libertad de hacerlo, sino las premisas incongruentes desde donde arranca. Muestra de la historicidad no lineal, de la que no da cuenta Gudynas, de la producción en sociedad en Marx:

En la producción, los hombres no actúan solamente sobre la naturaleza, sino que actúan también los unos sobre los otros. No pueden producir sin asociarse de un cierto modo, para actuar en común y establecer un 
intercambio de actividades. Para producir, los hombres contraen determinados vínculos y relaciones sociales, y sólo a través de ellos, es como se relacionan con la naturaleza y como se efectúa la producción." (Marx 1968: 37).

En el artículo que estamos usando de ilustración, Gudynas propone una separación analítica, como se dijo, entre "producción” y “apropiación”. A primera vista, tiene sentido en tanto se construye su articulación recíproca en el tránsito de lo abstracto a lo concreto. Pero en realidad no es así. Lo que plantea Gudynas es una articulación de lo general (MP) a lo particular (MA), desconsiderando el problema metodológico respecto del cual la abstracción (que no es lo mismo lógicamente que una generalización) cumple un papel relevante e inamovible en Marx.

La distinción que sugiere Gudynas, si se quiere plantear desde una complementariedad con Marx, no se sostiene. Por ejemplo, en la famosa Introducción de 1857, se establece la unidad entre producción y apropiación, al mismo tiempo que arremete contra quienes operan analíticamente esa separación:

Toda producción es apropiación por parte del individuo en el seno y por intermedio de una forma de sociedad determinada. En este sentido, es una tautología decir que la propiedad (la apropiación) es una condición de la producción. (Marx 1968: 7).

Por otro lado, Gudynas no repara en las diferencias conceptuales y de cambio de problemática a lo largo de la trayectoria teórica de Marx, como si el significado de la "producción" hubiese tenido el mismo sentido en "La Ideología Alemana" (1846) que en "El Capital” (1867) (Althusser, 1967). Sobre estos cambios en Marx se ha discutido bastante, lo importante, consideramos, es el reconocimiento de que los conceptos no son meros significantes transferibles sin modificar la sustancia de la problemática en la que ellos adquieren un sentido determinado.

En El Capital, MP es la unidad cuyo examen exhibe el conjunto de categorías que develan el secreto de la producción de capital: mercancía, valor de uso, valor de cambio, valor, trabajo abstracto, trabajo concreto, trabajo privado independiente, fetichismo de la mercancía, el secreto del dinero, etc. Trasplantar el concepto MP como si fuera únicamente una forma general, sin considerar la complejidad de la constelación de categorías que lo acompañan, o no argumentar su no uso, desdibuja en realidad lo propuesto por Marx y no se aborda su obra, por lo tanto, en diálogo crítico con ella. 


\section{Marx: ¿un marco conceptual de países industrializados?}

Otro punto a examinar dentro de los límites que Gudynas adjudica al concepto de MP de Marx, es la idea de que estos se originan desde "marcos conceptuales propios de países industrializados" (Gudynas, 2016: 99). Esa visión de Gudynas tiene un contenido muy apropiado cuando se trata de dar visibilidad crítica a una multitud de epistemologías que claramente desdibujan o socavan los conocimientos producidos en otras latitudes que no sean Europa o EEUU. Podría, a partir de ello, discutirse si es que Marx es o no eurocéntrico o hasta qué punto consideraba la realidad de otros pueblos que no sean los europeos. No obstante, no es lo que nos interesa discutir aquí.

Desde el punto de vista de lo que se está debatiendo acá, lo problemático es el hecho de que la pura constatación de provenir de países industrializados exima a Gudynas de presentar una argumentación más acuciosa respecto de los elementos que deja de lado por tener un objeto de estudio ajeno a América. Además, tampoco se evidencia en el artículo por qué no servirían para analizar a fondo la realidad de Latinoamérica: ¿cuáles serían esos elementos de marco conceptual insuficientes para países no industrializados? ¿A qué discusiones teóricas se está remitiendo Gudynas para descartar esos marcos, sea cuáles sean? No están explicitados, ni siquiera a pie de página.

Uno de los elementos que se mencionan, o solo desde su acepción economicista, es el de "renta". Generalmente, en este y otros textos, se la equipara a un Commodity o a una simple ganancia por "ventaja comparativa". Sin embargo, es sabido que, en Marx, y en un largo debate que siguió tras su muerte, hasta hoy, la categoría es más compleja que un mero concepto económico. No es él quien la inventa, pero es con él con quien adquiere una alta densidad. No es posible desarrollar aquí por qué la renta de la tierra es un elemento central en el pensamiento marxiano, hay abundante literatura reciente que busca argumentarlo (Caligaris 2014). Lo que sí se debe destacar, es que las distintas formas de renta de la tierra (diferencial I y II, absoluta y de monopolio) son indispensables e ineludibles para entender la conflictividad socio ambiental en América, de hecho, permite comprender la influencia social de un tipo particular de empresario capitalista, el rentista.

No nos podemos extender, pero una definición posible de la renta propiamente capitalista es "La forma social históricamente específica que emerge de esa base material en tanto los condicionamientos particulares en cuestión son objeto de apropiación privada en el modo de producción capitalista. Y la 
forma de esta apropiación privada es a potestad jurídica de ejercer el monopolio sobre la porción del suelo en que dichos condicionamientos operan" (Iñigo Carrera 2017: 5).

Esta tendencia general es apreciable en territorios avocados a la producción de mercancías de las cuales brota el beneficio de la renta de la tierra: petróleo, productos agrarios, minería, etc. La búsqueda incesante de este beneficio produce formas de control territorial y de organización del trabajo, modos de metabolizar ecosistemas para producir espacios de acumulación de capital y el fortalecimiento de grupos económicos y políticos que operan como personal que viabiliza la reproducción del rentismo.

Así, el rentismo se extiende como realidad social y en tanto mecanismo para constituir poderes (empresariales, políticos, ideológicos, etc.) que se organizan en función de la captación de los distintos tipos de renta de la tierra. Los regímenes a los que se refiere Gudynas, los avatares del llamado "ciclo progresista", están marcados por la influencia de la renta de la tierra. En ese sentido, ¿es posible impugnar esta categoría por el hecho de haber sido elaborada en el marco europeo industrializado? ¿No logra explicar una parte importante de las realidades de América Latina? Por supuesto, no quiere decir que explican todo o son el único mecanismo general que se reproduce en esta región, pero sí permiten explicar dinámicas fundamentales. ¿Acaso no son útiles los modos concretos de generación y apropiación de renta de la tierra, y todo lo que ello provoca, para comprender los extractivismos? Es posible que por el hecho de haberse pensado en Europa requieren una actitud crítica, pero también reconocimiento de aquello que es útil.

\section{Extractivismo: ¿relación social distinta al capital?}

Otra arista sobre el problema de los modos de producción es que Gudynas les vuelve a asignar una dimensión preponderantemente económica, en su sentido más literal: "la complejidad de emprendimientos, como la gran minería, los monocultivos de soja o la explotación petrolera en la Amazonia, no puede ser analizado únicamente desde una mirada económica, sea convencional o incluso heterodoxa." (Gudynas 2016: 100). Ante ello, argumenta que las complejidades de los extractivismos revelan otros nudos de conflicto (propiedad, Estado, rol de las empresas o de las comunidades, etc.) y que, según él, "expresan distintas relaciones sociales", que el concepto de MP no alcanza atender políticamente. 
Nuevamente, es difícil estar en desacuerdo con el sentido de la afirmación, por simple que sea: la realidad es compleja y multidimensional. Es cierto. Pero la generalidad de su afirmación se basa en una idea errónea en la que MP sería un concepto solo económico, en su acepción más reducida, lo cual no es efectivo. Por otro lado, para Gudynas, el concepto no daría cuenta de otras relaciones sociales, o sea, que la producción capitalista tiene exterioridades que operan con autonomía (él no distingue si de forma absoluta o relativa ni en virtud de qué criterios son “otras relaciones”). Nos referiremos a estas dos problemáticas.

Respecto al modo de producción como concepto económico. Marx se refiere a él principalmente como una relación social, incluso como una configuración socioambiental: “el trabajo es, en primer término, un proceso entre el hombre y la naturaleza, proceso en que el hombre realiza, regula y controla, mediante su propia acción, su intercambio orgánico con la naturaleza.” (Marx 2010: 185). Es factible decir que el concepto MP es económico por su contenido, pero su examen expresa una relación y un proceso social que se moviliza por actores sociales con agencia e intereses. Es cierto que los manuales marxistaleninistas, el diamat, dicen lo contrario, pero de ello no se puede hacer responsable a Marx. MP no es exclusivamente económico por hablar de "producción", sino que es una abstracción que muestra un contenido económico específico, formas de producir y reproducir la vida material de la sociedad, pero siendo al mismo tiempo y articuladamente un modo de relación social históricamente específica.

Al mismo tiempo, esta visión economicista sobre el MP, conspira contra la posibilidad de articular perspectivas de conjunto, con visión de totalidad, de la sociedad. Al ser considerado fundamentalmente como un concepto económico, quedan fuera de él un amplio arco de dimensiones de la sociedad. La idea de que hay "otras relaciones" no es exacta. Por supuesto, no porque no existan estados, regímenes de propiedad, comunidades en conflicto, etc., sino porque i) el capital es una relación social general, por lo tanto, tiende a englobar en su dinámica al conjunto de vínculos y conflictos sociales, sin implicar necesariamente una jerarquía ii) esas “otras” relaciones que presenta Gudynas, no son entendibles, en los marcos históricos actuales, sin señalar su unión con la relación social general que es el capital. Esta relación, según Marx, tiende a subordinar el conjunto de vínculos sociales al proceso de valorización del valor y, desde ese plano, es un principio organizador del Estado o la propiedad (Caligaris 2012). No es que estas sean "esferas" separadas o abstracciones funcionales, tales como las "comunidades", "extractivismos", "regímenes", etc. 


\section{Extractivismos: ¿un sector productivo?}

Otra afirmación de Gudynas: "los extractivismos en sentido estricto no son un sector 'productivo', ni tampoco una 'industria', tal como plantean los defensores de estos emprendimientos" (Gudynas 2016: 100). Aquella tendencia tal vez es cierta si se la mide desde el punto de vista de los indicadores de "crecimiento y desarrollo" convencionales, como el PIB, balanzas de pago, etc. Hablar de los extractivismos, en ese caso, sería otra forma de dar cuenta de asimetrías de América Latina respecto de otras zonas del mundo que, bajo este parámetro sí estarían industrializadas Es evidente que existen asimetrías indisimulables y su origen, carácter, tendencias y proyecciones suscitan hasta el día de hoy un debate. Ahora bien, lo que nos interesa poner en el centro es que la idea de que "industria" es algo así como equivalente a "sector secundario" de la economía, que enseñan en los manuales, es ajena a Marx. Como en todo, en realidad, Gudynas puede no estar de acuerdo con Marx, pero no es lícito pretender montar su concepto de MA sobre una categorización torcida de lo que para Marx es industria, concepto a su vez vinculado al de MP.

En ese plano, no se trata de que Marx no distinga en su análisis las especificidades de las industrias, bancos, comercio, etc., y sus formas de obtener renta, interés, ganancia en tanto capitales concretos. En cambio, para él el hecho de que el capital sea industrial tiene que ver, en primera instancia, con la capacidad de generar valor, en cualquier cantidad. Tomemos una cita que bien podría aplicarse a las mercancías de uso extractivistas, las "materias primas":

Al transformar el dinero en mercancías, que sirven de materias primas para la creación de un nuevo producto o de factores del proceso de trabajo, al incorporar a su objetividad muerta fuerza de trabajo viva, el capitalista convierte el valor, el trabajo pretérito objetiva, muerto, en capital, en valor que se valoriza a sí mismo, en un monstruo animado que se lanza a 'trabajar' cual si tuviera dentro del cuerpo el amor. (Marx 2010: 202).

No es una afirmación poética, sino que describe el proceso general del paso del valor, como actividad humana cristalizada, hacia la valorización, la creación de capital. En esa dirección: ¿produce valor el considerado por Gudynas sector extractivista, no industrial? Pareciera posible inferir que la "industria extractiva", como es denominada en El Capital, en tanto sea parte del proceso de valorización, del “consumo de la fuerza de trabajo por el capitalista” (Marx 2010: 193), sí está en condiciones de generar valor y/o de apropiar plusvalía proveniente de otras actividades por medio del mecanismo de renta de la tierra: 
La apropiación de renta tiene en su base el monopolio sobre l tierra. Pero como cualquier otra porción de riqueza social, no brota de este monopolio. Brota del trabajo social realizado de manera privada e independiente, bajo el comando del capital, por los obreros vendedores de fuerza de trabajo Más concretamente aún, en tanto se trata de una porción de dicho trabajo social que excede a la reproducción de la fuerza de trabajo que la produce, la renta de la tierra es una porción del producto del plus trabajo rendido por los obreros. El monopolio sobre la tierra da a los terratenientes títulos sobre una parte de la plusvalía en cuya producción, como ya lo remarcamos, no han tenido arte ni parte." (Carrera 2017: 85).

En otras palabras, en la imposibilidad de reconocer en el extractivismo un sector productivo, desde el punto de vista de su participación en la generación de valor, se encuentra latente el riesgo de no captar formas históricas y cursos de explotación identificables únicamente a través de la afirmación del extractivismo como actividad capitalista y, por lo tanto, analizado como tal.

Nuevamente: Gudynas no está obligado a compartir la misma idea de industria o sector productivo que Marx. Lo que no puede hacer es construir propuestas desde ausencias o confusiones inexistentes en Marx. Otra vez una visión de raíz economicista sobre lo que es "producción” le impide ver los potenciales analíticos expuestos explícitamente en Marx.

\section{Sobre el valor como categoría complementaria al modo de producción capitalista}

Volvamos una vez más sobre el valor. En el artículo que estamos comentando, Gudynas afirma que el concepto de MP de Marx permite considerar las múltiples “formas de asignar valor”. Detengámonos en este punto. En primer lugar, en la variante económica más convencional del vocablo: "el valor se asigna", como si se tratara de una magnitud puramente económica. En segundo lugar, detenerse en el tratamiento del MP como si fuera una categoría que pudiera operarse o desecharse sin mediaciones ni exponer modalidades sumamente concretas de “asignar valor”. Por último, Gudynas pareciera adjudicar a Marx una confusión entre valor y valor de cambio, refiriéndose en su artículo como "valor" a lo que en realidad es "valor de cambio" De hecho, es muy difícil no distinguir el secreto del valor de cambio una vez leído El Capital (Marx 2010: 52).

Muy por el contrario, lejos de ser una categoría económica en su sentido restringido, el valor es una forma de organización social, un núcleo del concepto de MP en Marx. En el capítulo I de El Capital, se exponen 
claramente sus fundamentos: una sociedad de productores privados independientes cuyos trabajos se conectan e intercambian entre sí porque comparten una sustancia social común, el tiempo de trabajo abstracto socialmente necesario que se requiere para producir determinadas mercancías: el valor, con todo el entramando histórico que supone que la sociedad tienda a organizarse preponderantemente para producir mercancías con tales atributos sociales. Las mercancías del extractivismo, que se configuran en todo momento a través de la naturaleza extra-humana, no escapa a esta tendencia. (Moore 2014).

Con todo, no es solo la constatación del valor, su magnitud y sustancia social, lo que aporta Marx, sino la demostración de que el motor de la sociedad actual es producir y apropiar más valor, activar procesos que lo acrecienten, valorizar el valor. De hecho, este sujeto autónomo de la vida social, el valor que se valoriza, es el proceso de producción de capital, un sujeto que se produce a sí mismo ampliándose como una relación social general, conformando un modo de producción. Así, la generación de capital es esencialmente la reproducción de una relación social que involucra en todo momento tipos de metabolismos-interacciones-sociedad-naturaleza.

¿Por qué entonces Gudynas le asigna en su artículo un papel tan poco relevante al potencial analítico del MP? Marx inicia El Capital tomando como punto de partida "las sociedades en que impera el modo de producción capitalista", tarea que iba a ocupar seis tomos similares al que él vio terminado, solo el primero, pero que, sin embargo, hoy se conocen otros dos tomos y además cuadernos preparatorios de redacción, como los Grundisse. Para Gudynas estas fuentes disponibles no parecen relevantes a la hora de justificar su propuesta de "complementar" con su propuesta de MA.

\section{El modo de producción como proceso "esencialmente entre humanos"}

Por último, pero ya señalando una idea a nuestro juicio totalmente rebatible, Gudynas argumenta que los "modos de producción lidian con procesos que se dan esencialmente entre humanos" (Gudynas 2016: 102). Esta opción que toma, ya no se trata de una simple omisión, como en los otros casos, sino de un planteamiento derechamente falso. No sólo inválido para un momento particular de la trayectoria teórica de Marx, sino falso para casi la totalidad: 
a) 1844: En la práctica, el hombre vive solo de estos productos naturales, ya sea en forma de alimentos, calor, vestido, vivienda, etcétera. La universalidad del hombre, aparece en la práctica en la universalidad que constituye toda la naturaleza en su cuerpo inorgánico. (Marx 2012: 110).

b) 1846: La producción real de la vida se revela como algo protohistórico, mientras que la historicidad se manifiesta como algo separado de la vida usual, como algo extra y supraterrenal. De este modo, se excluye de la historia el comportamiento de los hombres hacia la naturaleza, lo que engendra la antítesis de naturaleza e historia. Por eso, esta concepción solo acierta a ver en la historia los grandes actos políticos y las acciones del estado, las luchas religiosas y las luchas teóricas en general, y se ve obligada a compartir, especialmente, en cada época histórica, las ilusiones de esta época. (Marx \& Engels, 2011).

c) 1847: En la producción los miembros de la sociedad hacen que los productos de la naturaleza resulten apropiados a las necesidades humanas (los elaboran, los conforman); la distribución determina la proporción en que el individuo participa de estos productos; el cambio le aporta los productos particulares por los que él desea cambiar la cuota que le ha correspondido a través de la distribución; finalmente, en el consumo los productos se convierten en objetos de disfrute, de apropiación individual (Marx 1968: 9).

d) 1867: En su producción el ser humano puede proceder únicamente como la naturaleza misma, es decir, solo puede alterar la forma de las materias. Y aún más: incluso en este trabajo de transformación se apoya constantemente en las fuerzas naturales. El trabajo no es, por consiguiente, la única fuente de los valores de uso que produce, de la riqueza material. (Marx 2010: 57).

e) 1872: La vida a costa de trabajo ajeno será cosa del pasado. ¡No habrá más Gobierno ni Estado separado de la sociedad! La agricultura, la minería, la industria, en fin, todas las ramas de la producción se organizarán gradualmente de la forma más adecuada. La centralización nacional de los medios de producción será la base nacional de una sociedad compuesta de la unión de los productores libres e iguales, dedicados a un trabajo social con arreglo a un plan general y racional. Tal es la meta humana a la que tiende el gran movimiento económico del siglo XIX. (Marx 2019). 
f) 1875: El trabajo no es la fuente de toda riqueza. La naturaleza es la fuente de los valores de uso ( ¡que son los que verdaderamente integran la riqueza material!), ni más ni menos que el trabajo que no es más que la manifestación de una fuerza natural, la fuerza de trabajo del hombre” (Marx \& Engels 1984: 420).

g) 1881: Han pasado ya los tiempos en que la agricultura rusa no necesitaba más que tierra y agricultor parcelario pertrechado con aperos más o menos primitivos. Estos tiempos han pasado con tanta rapidez porque la opresión del agricultor contagia y esteriliza su campo. Le hace falta ahora el trabajo colectivo organizado en gran escala" (Marx 2019).

\section{Conclusión}

No parece lícito entonces, proponer una apuesta complementaria en base a falsas ausencias o, lisa y llanamente, torsiones. Es discutible hasta qué punto es productivista la trayectoria de Marx, el rendimiento y límites del concepto de modo de producción; la relevancia que tienen conceptos como "metabolismo", "naturaleza inorgánica", etc.; lo prometeico de su visión entre otras problematizaciones posibles. Pero negar el reconocimiento a la potencia de un concepto tan fundamental como el modo de producción (y sus múltiples implicaciones), no permite el diálogo, clausura y limita el aporte que puede hacer Marx a las actuales discusiones sobre la situación socio ambiental del mundo. Que Gudynas proponga marcos conceptuales, los cuales sirven a muchas agrupaciones en lucha socio ambiental, pero que no lo haga desestimando por omisión, o tal vez sin conocer a fondo, la obra de otros pensadores.

\section{Referencias bibliográficas}

Althusser, L. (1967). La revolución teórica de Marx. Buenos Aires: Siglo XXI.

Caligaris, G. (2012). Clases sociales, lucha de clases y Estado en el desarrollo de la crítica de la economía política. En G. Caligaris , \& A. Fitzsimons, Relaciones económicas y políticas. Aportes para el estudio de su unidad con base en la obra de Karl Marx (págs. 72-91). Buenos Aires: Universidad de Buenos Aires.

(2014). Dos debates en torno a la renta de la tierra y sus implicancias para el análisis de la acumulación de capital en la Argentina. Razón y Revolución, 63-83.

Gudynas, E. (2016). Modos de producción y modos de apropiación. Una distinción a propósito de los extractivismos. Actuel Marx(20), 95-122.

Carrera, I.. (2017). La renta de la tierra. Formas, fuentes y apropiación. Buenos Aires: Imago Mundi. 
Marx, K. (1968). Trabajo Asalariado y Capital. Madrid : Ricardo Aguilera.

(1968). Introducción general a la crítica de la economía política. Córdoba: Pasado y Presente. (2010). El Capital. Santiago: LOM.

(2012). Manuscritos económico-filosóficos. México: FCE.

(2019). Proyecto de respuesta a la carta. Obtenido de Marxists.org: https://www.marxists.org/espanol/m-e/1880s/81-azasu.htm?fbclid=IwAR2Yv1hwYkh2S8kpBkogJKsspR-1-hjirWJe4V6hs-lEfy_W84RjvXyAqyo

(2019). La nacionalización de la Tierra. Obtenido de Marxists.org: https://www.marxists.org/espanol/m-e/1870s/lndl72s.htm?fbclid=IwAR35VBRZh7qB5ST1J1uWmAFMj3SGmUg2Y2HTPXRC5i9bRpK9KceXG181HM

Marx, C., \& Engels, F. (1984). Observaciones al Programa del Partido Obrero Alemán. En C. Marx, \& F. Engels, Obras Escogidas volumen 2 (págs. 420-436). Buenos Aires: Editorial Cartago.

(2011). La Ideología Alemana. En C. Marx, \& F. Engels, Textos escogidos (págs. 15-23). México DF: Ocean Sur.

Moore, J. (2014). Crisis: ¿ecológica o ecológico-mundial? Actuel Marx Intervenciones(17), LOM. 